\title{
Low miR-145 and high miR-367 are associated with unfavourable prognosis in resected nonsmall cell lung cancer
}

\author{
Marc Campayo*,f, Alfons Navarro", , Nuria Viñolas*, Tania Diaz", Rut Tejero", \\ Josep M. Gimferrer", Laureano Molins", Maria L. Cabanas ${ }^{+}$, \\ Jose Ramirez ${ }^{+}$, Mariano Monzo ${ }^{\#}$ and Ramon Marrades ${ }^{\S}$
}

ABSTRACT: The transcription factors SRY-related HMG box (SOX)2 and octamer-binding transcription factor (OCT) 4 regulate the expression of the miR-302-367 cluster. miR-145 regulates SOX2 and OCT4 translation and p53 regulates miR-145 expression. We analysed the expression of the miR-302-367 cluster and miR-145 and the mutational status of p53 in resected nonsmall cell lung cancer (NSCLC) patients and correlated results with time to relapse (TTR).

Tumour and paired normal tissue samples were obtained from 70 NSCLC patients. MicroRNA expression was assessed with TaqMan MicroRNA Assays. p53 exons 5 to 8 were sequenced.

miR-145 was downregulated $(p<0.0001)$ and miR-367 was upregulated $(p<0.0001)$ in tumour compared with normal tissue. Mean TTR was 18.4 months for patients with low miR-145 levels and 28.2 months for those with high levels $(p=0.015)$. Mean TTR was 29.1 months for patients with low miR-367 levels and 23.4 months for those with high levels $(p=0.048)$. TTR was shorter for patients with both unfavourable variables $(p=0.009)$. Low miR-145 expression $(p=0.049)$, the combination of unfavourable microRNA levels $(p=0.02)$ and the combination of low miR-145 with $p 53$ mutations $(p=0.011)$ were independent markers of shorter TTR.

In conclusion, miR-145 and miR-367 expression could be novel markers for relapse in surgically treated NSCLC. p53 may play a role in modulating miR-145 expression in NSCLC.

KEYWORDS: miR-145, miR-367, nonsmall cell lung cancer, p53, prognostic markers

ung cancer is the first cause of cancer death in the world [1], and $\sim 85 \%$ of lung cancers are nonsmall cell lung cancer (NSCLC). $<30 \%$ of NSCLCs are diagnosed at an early stage, when the main treatment is surgical resection. The relapse rate after surgery is high (20-70\%, depending on disease stage), and stage II-III patients are routinely treated with adjuvant chemotherapy, which has been shown to improve survival in several randomised clinical trials [2-5]. However, adjuvant chemotherapy is not routinely administered for stage I disease [2], although it has been postulated that high-risk stage I patients could also benefit from this treatment [6]. Biomarkers to predict the risk of relapse would thus be a useful tool for risk stratification and selection of patients for adjuvant treatment.

The transcription factors SRY-related HMG box (SOX)2, octamer-binding transcription factor (OCT)4 and NANOG are essential for early embryonic development and for maintenance and regulation of stemness in human embryos and adult tissues [7, 8]. Dysregulation of these embryonic transcription factors has been associated with tumour growth and progression in several cancers $[9,10]$. In NSCLC, SOX2 is strongly and diffusely expressed in $\sim 90 \%$ of squamous cell carcinomas and $20 \%$ of adenocarcinomas [11]. SOX2 is a 3q-amplified oncogene in lung and oesophageal squamous cell carcinoma [12], and $3 q$ amplification has been shown to separate high-from low-grade dysplasia in bronchial biopsies [13]. Moreover, clinical progression of pre-invasive bronchial lesions has been associated with SOX2 amplification [13]. SOX2 expression is also higher in poorly differentiated than in well differentiated tumours [14]. Interestingly, not only does SOX2 overexpression stimulate cellular migration and anchorage-independent growth in cell cultures [15], but it is also oncogenic in mouse models [16]. SOX2 expression, detected by immunohistochemistry, has been proposed as an independent marker of poor outcome in stage I lung adenocarcinoma [17].
AFFILIATIONS

*Dept of Medical Oncology, ICMHO, Hospital Clínic de Barcelona, IDIBAPS, Barcelona,

\#Human Anatomy and Embryology Unit, Laboratory of Molecular

Oncology and Embryology, School of Medicine, University of Barcelona, IDIBAPS, Barcelona,

"Dept of Thoracic Surgery, ICT, Hospital Clínic de Barcelona, IDIBAPS, Barcelona,

${ }^{+}$Dept of Pathology, CDB, Hospital Clinic de Barcelona, University of Barcelona, IDIBAPS, CIBERES,

Barcelona, and

${ }^{\S}$ Dept of Pneumology, ICT, Hospital

Clínic de Barcelona, IDIBAPS,

CIBERES, Barcelona, Spain.

${ }^{f}$ These authors contributed equally to this work.

CORRESPONDENCE

R. Marrades

Dept of Pneumology, ICT

Hospital Clínic de Barcelona

Villarroel 170

08036 Barcelona

Spain

E-mail: marrades@clinic.ub.es

Received:

March 222012

Accepted after revision:

June 292012

First published online:

July 262012 
MicroRNAs (miRNAs) are small noncoding RNAs (22-24 nucleotides in length) that negatively regulate RNA translation to protein. miRNAs are essential for regulating cell proliferation, differentiation and maintenance of stemness [18]. SOX and OCT4 bind to the miR-302 promoter region and are essential for the expression of its members (miR-302a-a*-b-b*c-c*-d- and miR-367) $[18,19]$ in human embryonic stem cells. miR-145 regulates SOX2 and OCT4 expression and blocks self-renewal in human embryonic stem cells and induces expression of mesodermal and ectodermal differentiation markers [20].

Mutations of the central tumour suppressor p53, which regulates the maturation of several miRNAs, have been shown to lead to attenuation of miRNA processing activity. Interestingly, $\mathrm{p} 53$ regulates the expression of miR-145 by binding to its promoter region [21].

These data indicate that the miR-302-367 cluster, miR-145 and p53 work together to influence growth and differentiation in human embryonic stem cells. However, the relevance of these three factors in early-stage NSCLC remains to be elucidated. In order to shed light on this potential role of the miR-302-367 cluster, miR-145 and p53, we have analysed the expression of the miRNAs and the mutational status of p53 in surgically resected NSCLC patients and correlated results with time to relapse (TTR).

\section{MATERIALS AND METHODS}

\section{Study population}

70 fresh tumour samples and 70 paired normal tissue samples from NSCLC patients who underwent complete surgical resection in our institution were prospectively collected between June 2007 and December 2009. Immediately after surgery, samples were labelled, frozen at $-80^{\circ} \mathrm{C}$ and kept for further processing. All patients had pathologically confirmed stage I-III NSCLC, Eastern Cooperative Oncology Group performance status $0-2$, were aged $>18$ years and had adequate organ function. Approval for the study was obtained from the Institutional Review Board of the Hospital Clinic of Barcelona, Spain. Written informed consent was obtained from each participant in accordance with the Declaration of Helsinki.

\section{RNA extraction and miRNA quantification}

Total RNA was extracted from fresh frozen tumour and normal tissues using Trizol (Invitrogen by Life Technologies, Carlsbad, CA, USA) following the manufacturer's protocol. RNA concentration was obtained using NanoDrop ND-1000 Spectrophotometer (Fisher Scientific, Madrid, Spain). $10 \mathrm{ng}$ of total RNA was used for each miRNA quantification. We performed two independent copies in a single run. miRNA detection was performed using commercial assays (TaqMan microRNA assays; Applied Biosystems, Foster City, CA, USA) for miR-145, miR-302a-b-c-d and miR-367, as described previously [22], using an Applied Biosystems 7500 Sequence Detection System. Relative quantification was calculated using $2^{-\Delta \Delta \mathrm{Ct}}$, where $\mathrm{Ct}$ is cycle threshold. Normalisation was performed with miR-191 as it was found to be the most stably expressed miRNA in frozen lung specimens [23]. We used the median of normal tissue expression as calibrator.

\section{p53 mutation analysis}

PCR was performed on 50-ng DNA samples to identify p53 mutations. The mutation analysis included p53 exons $5-8$. The following primers were used: p53 exon 5 forward $5^{\prime}$ GTTTCTTTGCTGCCGTCTTC-3', reverse 5'-GAGCAATCAG TGAGGAATCAGA-3'; p53 exon 6 forward 5'-AGAGACGA CAGGGCTGGTT-3', reverse 5'-CTTAACCCCTCCTCCCAG AG-3'; p53 exon 7 forward 5'-TTGCCACAGGTCTCCCC AA-3', reverse 5'-AGGGGTCAGAGGCAAGCAGA-3'; and p53 exon 8 forward 5'-GGGACAGGTAGGACCTGATTT-3', reverse 5'-TAACTGCACCCTTGGTCTCC-3'. The PCR products were analysed by agarose gel electrophoresis, purified

\begin{tabular}{|c|c|c|c|c|}
\hline \multirow[t]{2}{*}{ Characteristic } & \multirow[t]{2}{*}{ n (\%) } & \multicolumn{3}{|c|}{$\mathrm{p}$-value } \\
\hline & & TTR & $\operatorname{miR}-145^{\#}$ & $\operatorname{miR}-367^{\#}$ \\
\hline \multicolumn{5}{|l|}{ Sex } \\
\hline Male & $58(82.9)$ & 0.02 & 0.535 & 0.545 \\
\hline Female & $12(17.1)$ & & & \\
\hline \multicolumn{5}{|l|}{ Age years } \\
\hline$\leqslant 65$ & $31(44.3)$ & 0.965 & 0.050 & 0.655 \\
\hline$>65$ & $39(55.7)$ & & & \\
\hline \multicolumn{5}{|l|}{ Performance status } \\
\hline 0 & $7(10)$ & 0.861 & 0.5 & 0.277 \\
\hline 1 & $63(90)$ & & & \\
\hline \multicolumn{5}{|l|}{ Stage } \\
\hline । & $44(62.9)$ & 0.374 & 0.758 & 0.874 \\
\hline$\|$ & $12(17.1)$ & & & \\
\hline III & $14(20)$ & & & \\
\hline \multicolumn{5}{|l|}{ Histology } \\
\hline Adenocarcinoma & $36(51.4)$ & 0.49 & $0.364^{\circ}$ & $0.926^{\circ}$ \\
\hline $\begin{array}{l}\text { Squamous cell } \\
\text { carcinoma }\end{array}$ & $28(40)$ & & & \\
\hline Others & $6(8.6)$ & & & \\
\hline \multicolumn{5}{|l|}{ Type of surgery } \\
\hline Lobectomy/bilobectomy & $59(84.3)$ & 0.27 & & \\
\hline Pneumonectomy & $5(7.1)$ & & & \\
\hline Atypical resection & $6(8.6)$ & & & \\
\hline \multicolumn{5}{|l|}{ Smoking history } \\
\hline Current smoker & $22(31.4)$ & 0.184 & 0.082 & 0.587 \\
\hline Former smoker & $40(57.1)$ & & & \\
\hline Never-smoker & $6(8.6)$ & & & \\
\hline Unknown & $2(2.9)$ & & & \\
\hline \multicolumn{5}{|l|}{ Adjuvant chemotherapy } \\
\hline Yes & $15(21.4)$ & 0.774 & & \\
\hline No & 55 (78.6) & & & \\
\hline \multicolumn{5}{|l|}{ Relapse } \\
\hline No & $47(67.1)$ & & & \\
\hline Yes & $23(32.9)$ & & & \\
\hline \multicolumn{5}{|l|}{ p53 mutated } \\
\hline Yes & $13(20.3)$ & 0.002 & 0.009 & 0.555 \\
\hline No & $51(79.7)$ & & & \\
\hline
\end{tabular}

TTR: time to relapse. ${ }^{\#}$ : t-test was used to compare miRNA levels with variables with two values and ANOVA for variables with more than two values; adenocarcinoma was compared only with squamous cell carcinoma. 
and used in two sequencing reactions per exon (forward and reverse), using the Big Dye Terminator Cycle Sequencing kit (version 3.1; Applied Biosystems). Reactions were loaded into an ABI-310 DNA sequencer (Applied Biosystems). All sequences were analysed with the SeqScape software (Applied Biosystems). The p53 mutation analysis was performed in only 64 patients as the remaining six patients had insufficient tissue for DNA extraction. Conditions are shown in detail in the online supplementary material.

\section{Statistical methods}

The objective of our study was to assess TTR, calculated from the time of surgical treatment to the date of relapse or last follow-up. TTR was calculated using the Kaplan-Meier method and compared using the log-rank test. Optimal cutoff points of miRNA expression data for TTR and overall survival were assessed by means of maximally selected logrank statistics [24] using the Maxstat package (version 2.8.1; $\mathrm{R}$ statistical package, Institute for Statistics and Mathematics, Vienna, Austria) and confirmed by the Kaplan-Meier test. All variables with a $\mathrm{p}$-value $\leqslant 0.1$ in the univariate analysis were included in a Cox multivariate analysis in order to calculate the independent odds ratios for TTR. All statistical analyses were performed with PAS W Statistics 18 (SPSS Inc., Chicago, IL, USA) and $R$ version 2.13. Statistical significance was set at $\mathrm{p} \leqslant 0.05$.

\section{RESULTS}

\section{Patient characteristics}

Table 1 shows the main characteristics of the 70 patients included in the analysis. $58(82.9 \%)$ patients were male. Their mean age was 67 years (range $46-83$ years). 59 (84.3\%) patients underwent a lobectomy or bilobectomy. All patients had pathological tumour stage I-III. $36(51.4 \%)$ patients had adenocarcinoma and 28 patients $(40 \%)$ had squamous cell carcinoma. $15(21.4 \%)$ patients received cisplatin-based adjuvant chemotherapy. At a mean follow-up of 17 months, 23 $(32.9 \%)$ patients had relapsed, five of whom $(21.7 \%)$ had received adjuvant chemotherapy.

\section{miRNA expression in normal and tumour tissue}

The normalised real-time PCR results showed that miR-145 expression was downregulated $(\mathrm{p}<0.0001)$ and miR-367

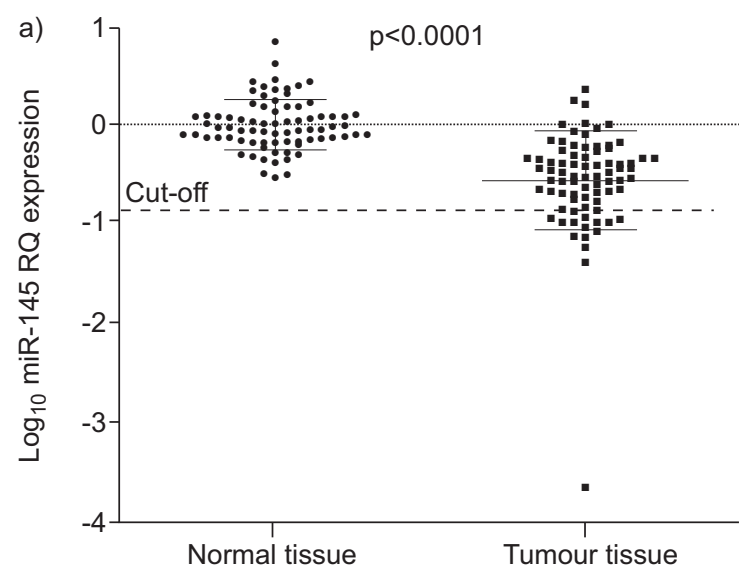

expression was upregulated $(\mathrm{p}<0.0001)$ in tumour tissue as compared with paired normal tissue samples. The mean fold change (relative quantitation $(R Q)=2^{-\Delta \Delta C t}$ ) was 0.28 for miR145 and 4.46 for miR-367 (fig. 1). Low miR-145 expression was associated with patients aged $>65$ years $(p=0.05)$. No other association between miRNA expression and clinical characteristics was observed (table 1).

\section{miR-145 and miR-367 expression, individually and in combination}

Overall mean TTR was 26.2 months. Mean TTR for females was 36.7 months versus 23.3 months for males $(p=0.02)$. In order to examine the prognostic implications of the expression levels of miR-145, miR-302a-b-c-d and miR-367, we used the cut-off point selected by the Maxstat package of R. This only identified significant cut-off points for miR-145 (cut-off RQ 0.95) and miR-367 (cut-off RQ 0.65). Both cut-off points discriminate two groups of patients: patients with or without overlapped expression with the normal tissue, as observed in figure 1 . When patients were divided according to the selected cut-off point, the mean TTR for patients with low miR-145 levels was 18.4 months versus 28.2 months for patients with high miR-145 levels ( $p=0.015$; fig. 2a). Mean TTR for patients with low miR-367 levels was 29.1 months versus 23.4 months for patients with high miR-367 ( $p=0.048$; fig. $2 b$ ). No other differences in TTR were observed according to clinical characteristics or miRNA expression levels.

In order to further explore the influence of miR-145 and miR367 , we then examined their effect in combination. When patients with both unfavourable variables (low-miR-145 and high miR-367 expression) were grouped together, mean TTR was 14.7 months for patients with both unfavourable variables versus 27.8 months for patients with only one or no unfavourable variable ( $p=0.009$; fig. 3$)$.

\section{p53 mutations and miR-145 expression}

p53 mutation status was successfully assessed in 64 patients, 13 $(20 \%)$ of whom harboured p53 mutations (table 2). The normalised real-time PCR results from the 64 tumour samples showed that miR-145 expression was downregulated in patients with p53 mutations and upregulated in patients with nonmutated p53 $(\mathrm{p}<0.009)$. The mean fold change between the

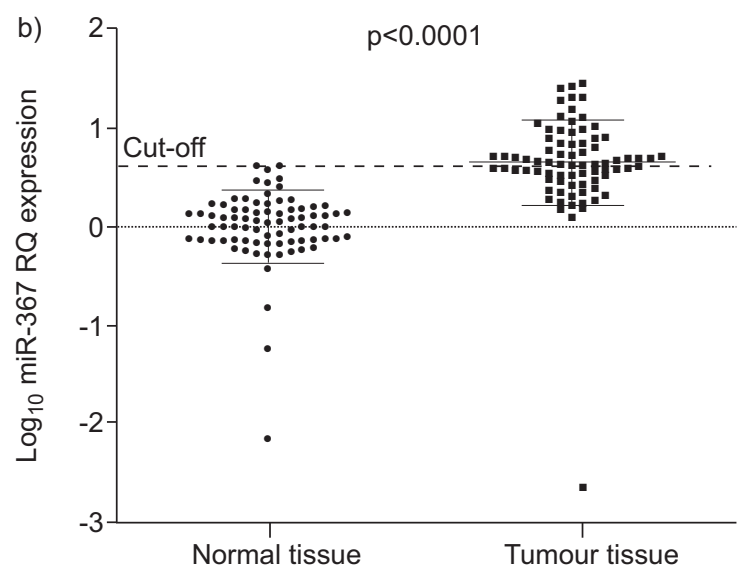

FIGURE 1. a) miR-145 and b) miR-367 expression in tumour and normal tissue. RQ: relative quantitation. 

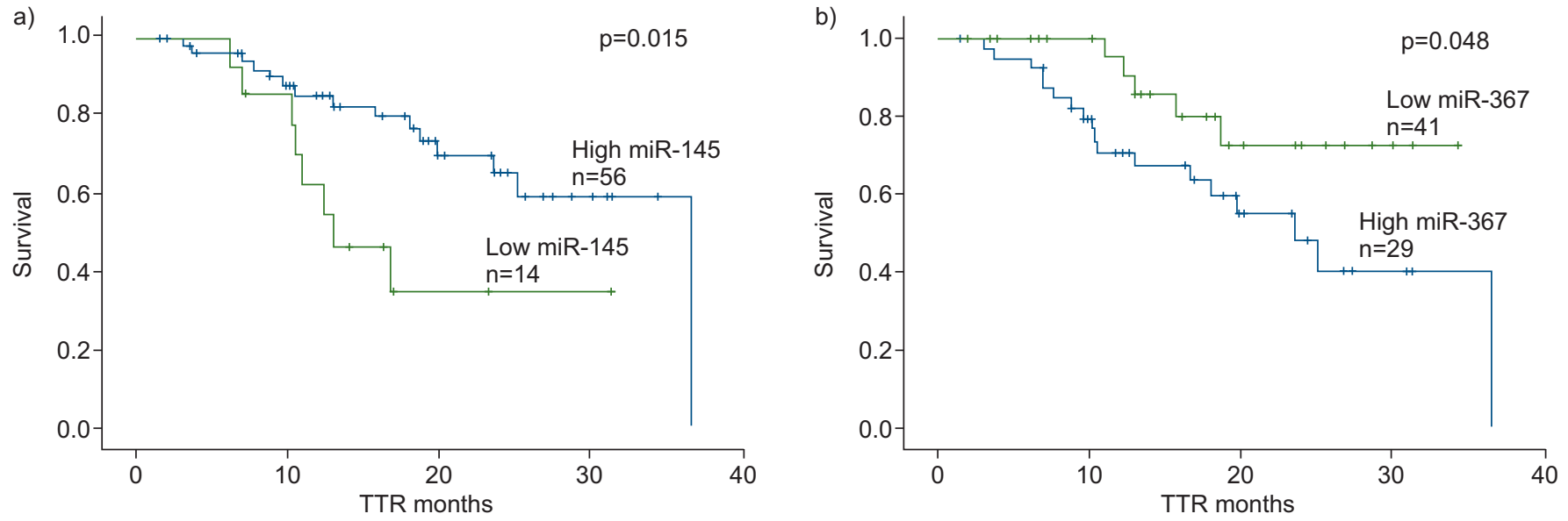

FIGURE 2. Kaplan-Meier curves for time to relapse (TTR) according to the level of expression of a) miR-145 and b) miR-367.

group with p53 mutations and the group with nonmutated p53 was 0.37 . The average $\Delta \mathrm{Ct}$ values were 0.67 for the group with mutated p53 and -0.71 for the group without mutations (fig. 4). Mean TTR was 28.69 months for the 13 patients with p53 mutations and 15.60 months for the remaining 51 without p53 mutations $(p=0.002)$ (fig. 5a). Mean TTR was 9.95 months for the six patients with both low miR-145 expression and p53 mutations and 27.38 months for the remaining 64 patients with low miR-145 expression but without p53 mutations $(p=0.00001)$ (fig. 5b).

\section{Multivariate analyses}

A multivariate analysis of TTR was performed including clinical variables with univariate log-rank $\mathrm{p}<0.1$, disease stage, miR-145 expression, miR-367 expression and p53 mutation status. Low miR-145 expression (OR 2.70, 95\% CI 1.05-7.26; $\mathrm{p}=0.049$ ) and p53 mutations (OR 3.53, 95\% CI 1.3-9.6; p=0.014) emerged as independent markers for shorter TTR, while stage I disease (OR 0.21, 95\% CI 0.068-0.657; p=0.007) was an independent marker for longer TTR.

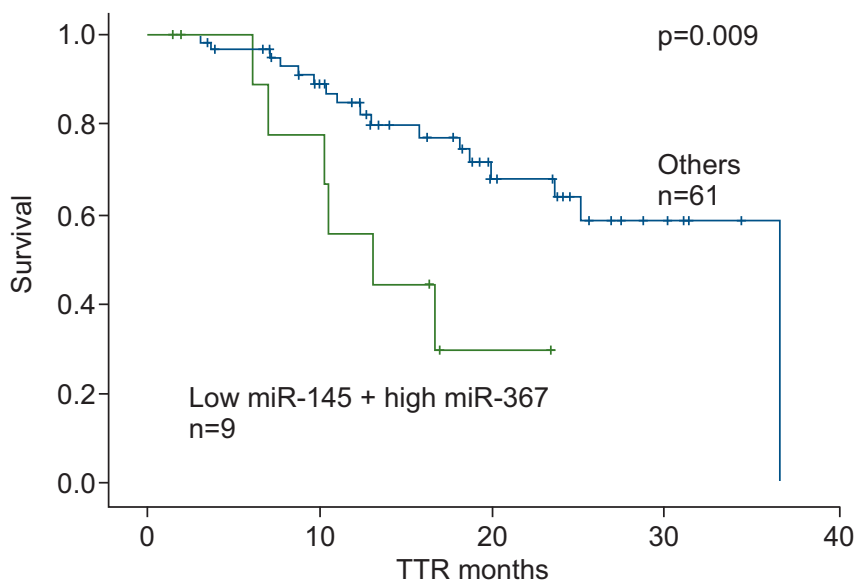

FIGURE 3. Kaplan-Meier curves for time to relapse (TTR) in patients with both unfavourable variables (low miR-145 and high miR-367) versus those with only one or no unfavourable variable.
A second multivariate analysis was then performed, including the same clinical variables but comparing unfavourable miRNA expression levels (low miR-145 plus high miR-367) versus other combinations and comparing low miR-145 expression with p53 mutations versus low miR-145 expression without p53 mutations. In this second multivariate analysis, the combination of unfavourable miRNA expression levels (OR 3.56, 95\% CI 1.20-10.40; $\mathrm{p}=0.02$ ) and the combination of low miR-145 with p53 mutations (OR 3.67, 95\% CI 1.34-9.98; $\mathrm{p}=0.011$ ) were independent markers for shorter TTR, while stage I disease continued to be a marker for longer TTR (OR 0.169, 95\% CI 0.05-0.52; p=0.002) (table 3).

\section{DISCUSSION}

The SOX2/OCT4/NANOG group of transcription factors is essential to maintaining the pluripotent embryonic stem cell phenotype. p53 enhances the post-transcriptional maturation of miR-145 [25], which regulates the expression of SOX2/OCT4 [20], while SOX2, OCT4 and NANOG act as upstream regulators of the miR-302-367 cluster [19]. Interestingly, both SOX2/OCT4/NANOG and miR-302-367 expression levels are high during the initial phases of embryonic development but

\begin{tabular}{|c|c|c|c|c|}
\hline TABLE 2 & p53 ms & tions & & \\
\hline Sample & Codon & $\begin{array}{l}\text { Nucleotide } \\
\text { change }\end{array}$ & $\begin{array}{l}\text { Amino acid } \\
\text { change }\end{array}$ & Exon \\
\hline 07-394 & 157 & GTC $>$ TTC & Val $>$ Phe & 5 \\
\hline $07-413$ & 141 & TGC $>$ GGC & Cys $>$ Gly & 5 \\
\hline $09-311$ & 157 & GTC $>$ TTC & Val>Phe & 5 \\
\hline $08-647$ & 129 & GCC $>$ GTC & $\mathrm{Ala}>\mathrm{Val}$ & 5 \\
\hline $07-326$ & 214 & $\mathrm{CAT}>\mathrm{GAT}$ & His $>$ Asp & 6 \\
\hline 07-306 & 213 & CGA $>$ TGA & Arg $>$ STOP & 6 \\
\hline $09-310$ & 196 & $C G A>T G A$ & Arg $>$ STOP & 6 \\
\hline 08-008 & 215 & AGT>ATT & Ser>Iso & 6 \\
\hline 09-022 & 242 & TGC $>$ AGC & Cys $>$ Ser & 7 \\
\hline $09-213$ & 248 & $\mathrm{CGG}>\mathrm{CAGG}$ & Insertion & 7 \\
\hline 08-206 & 272 & $\mathrm{GTG}>\mathrm{GAG}$ & Val $>$ Glu & 8 \\
\hline $09-327$ & 273 & CGT >CTT & Arg $>$ Leu & 8 \\
\hline 08-562 & 285 & $G A G>G T G$ & $\mathrm{Glu}>\mathrm{Val}$ & 8 \\
\hline
\end{tabular}




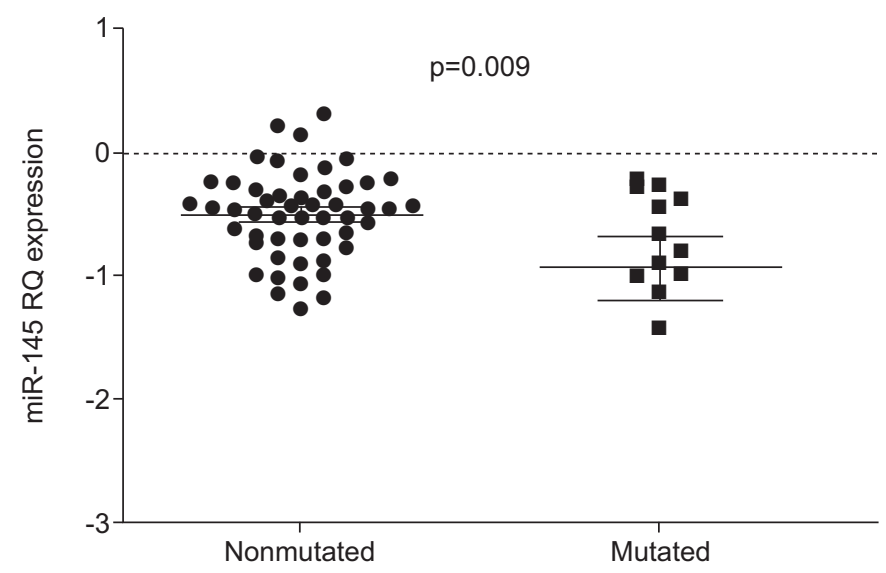

FIGURE 4. $p 53$ mutational status according to miR-145 expression levels. RQ: relative quantitation.

undergo rapid downregulation upon cell differentiation [26, 27]. Moreover, a study in several cell lines showed that ectopic expression of the miR-302-367 cluster was sufficient to reprogramme cells and transform them into pluripotent cells [28]. While it is clear that SOX2/OCT4/NANOG and their related miRNAs, the miR-302-367 cluster and miR-145, play a distinctive role in embryonic stem cells, this is the first study to examine the potential impact on prognosis of these embryonic miRNAs in surgically treated cancer patients.

The present study has shown significant differences in the expression levels of miR-367 and miR- 145 between tumour and normal tissue from surgically resected NSCLC patients. miR145 expression was lower in tumour than in normal tissue, which is similar to findings in embryonic stem cells and cancer cell lines. In human embryonic stem cells, miR-145 regulates SOX2 and OCT4 expression, inhibiting self-renewal and pluripotency [20], and in $\mathrm{CD}_{133^{+}}$cancer cell lines, miR-145 overexpression significantly reduced the proliferation capacity of cancer stem cells [29]. In the present study, patients with lower levels of miR-145 had a shorter TTR than those with

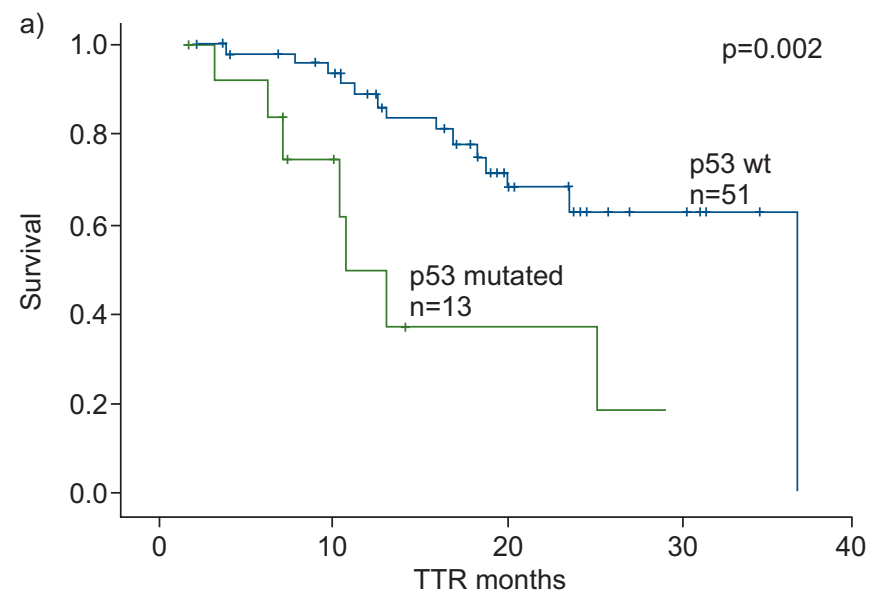

higher levels, suggesting that miR-145 may play the same inhibitory role in early-stage NSCLC.

In contrast to miR-145, miR-367 expression was significantly higher in tumour than in normal tissue, and patients with higher levels of miR-367 had a shorter TTR than those with lower levels. Along the same lines, experimental studies in human embryonic stem cells found that miR-367 can positively regulate cell self-renewal and maintain cell pluripotency by inhibiting cyclin D1/Cdk4 and activating transforming growth factor (TGF) $\beta$ nodal/activin [30]. It is known that SOX2/ OCT4/NANOG regulates the expression of the miR-302-367 cluster in embryonic stem cells, and experimental and clinical studies have shown a relationship between SOX2/OCT4/ NANOG and tumour growth and metastasis [17, 31]. Taken together, these findings indicate that high miR-367 expression may promote tumour development.

Recently, a significant correlation has been found between miR145 expression and p53 mutation status in both prostate tumour tissue and cancer cell lines [32]. p53-mutant prostate cancer samples and cell lines showed lower miR-145 expression compared with adjacent normal regions or non-mutated cell lines. In the present study, patients with p53 mutations and low miR-145 expression had worse prognosis than patients with nonmutated p53 and low miR-145. This is along the lines of findings in cell lines, where p53 mutations led to attenuation of miRNA processing activity, suggesting a tumour-suppressive role for p53 [25]. These data indicate that there may be an important link between p53 mutational status and miR-145 expression.

The multivariate analyses in the present study showed that low miR-145 expression in combination with high miR-367 expression was an independent marker of shorter TTR, indicating that in addition to playing a distinctive role in embryonic stem cells, miR-145 and miR-367 may also impact adult stem cells. It has recently been suggested that adult lung stem cells retain molecular characteristics that are typical of embryonic stem cells [33]. It could thus be postulated that the abnormal expression of miR-145 and miR-367 may be a requisite for the transformation of normal adult stem cells into cancer stem cells.

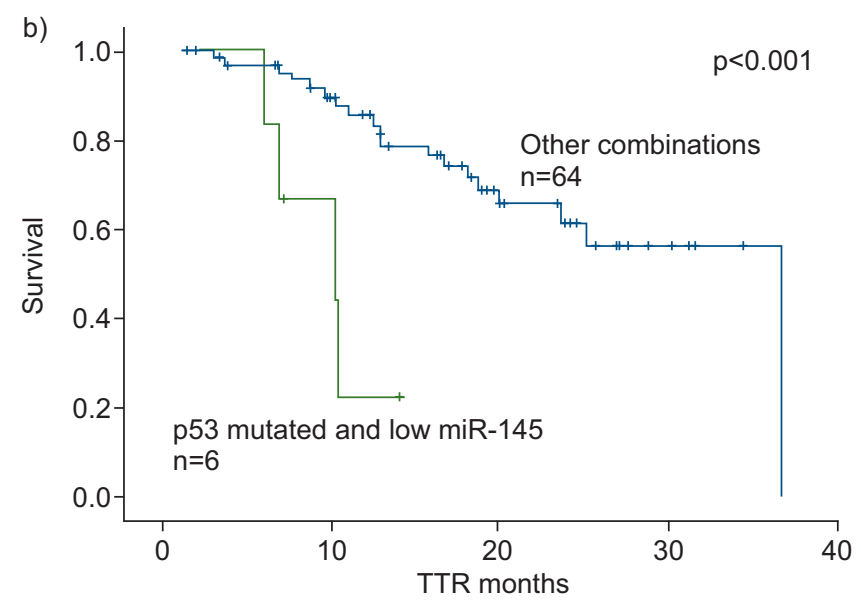

FIGURE 5. Kaplan-Meier curves for time to relapse (TTR) in a) patients with mutated or wild-type (wt) p53 and b) patients with both mutated p53 and low miR-145 expression versus all other patients. 


\begin{tabular}{|c|c|c|}
\hline Variable & OR $(95 \% \mathrm{Cl})$ & p-value \\
\hline \multicolumn{3}{|c|}{$\begin{array}{l}\text { Analysis with miRNA expression } \\
\text { levels considered separately }\end{array}$} \\
\hline Low miR-145 & $2.7(1.05-7.26)$ & 0.049 \\
\hline p53 & $3.53(1.3-9.6)$ & 0.014 \\
\hline Stage I disease & $0.21(0.068-0.657)$ & 0.007 \\
\hline \multicolumn{3}{|c|}{$\begin{array}{l}\text { Analysis including unfavourable }{ }^{\#} \\
\text { versus other combinations } \\
\text { of miRNA expression } \\
\text { and low miR-145 with or without } \\
\text { p53 mutations }\end{array}$} \\
\hline Low miR-145+high miR-367 & $3.56(1.2-10.40)$ & 0.02 \\
\hline Low miR-145+p53 mutations & $3.67(1.34-9.98)$ & 0.011 \\
\hline Stage I disease & $0.169(0.05-0.52)$ & 0.002 \\
\hline
\end{tabular}

To the best of our knowledge, the present study is the first to explore the potential implications for tumour progression of miRNAs related to early embryogenesis. While there are many recognised prognostic and predictive markers for NSCLC, including several gene signatures, miRNAs and miRNA signatures, the fact that miRNAs regulate the transcription of multiple target genes leads us to speculate that the analysis of miRNA expression may have further-reaching ramifications than that of gene expression. Although further studies are warranted, miRNA signatures may well be useful in predicting patients who will respond to certain chemotherapy regimens or who have a greater risk of relapse.

In summary, our findings provide the first hints that miR-145 and miR-367 expression may be a useful prognostic marker that could be used for risk stratification and selection of early NSCLC patients for adjuvant treatment. In addition, the potential role of p53 in modulating miR-145 expression warrants further investigation.

\section{SUPPORT STATEMENT}

This work was supported by grants from Fondo de Investigación Sanitaria (FIS 080135, 09 00547), Sociedad Española de Neumología y Cirugía Torácica (SEPAR 809-2009) and Societat Catalana de Pneumologia (SOCAP 2009). T. Diaz is a fellow supported by Agència de Gestió d'Ajuts Universitaris i de Recerca (AGAUR), Generalitat de Catalunya and Fondo Social Europeo. R. Tejero is a fellow of the University of Barcelona.

\section{STATEMENT OF INTEREST}

None declared.

\section{REFERENCES}

1 Jemal A, Siegel R, Xu J, et al. Cancer Statistics, 2010. CA Cancer J Clin 2010; 60: 277-300.

2 Arriagada R, Bergman B, Dunant A, et al. Cisplatin-based adjuvant chemotherapy in patients with completely resected non-small-cell lung cancer. N Engl J Med 2004; 350: 351-360.
3 Kato $\mathrm{H}$, Ichinose $\mathrm{Y}$, Ohta $\mathrm{M}$, et al. A randomized trial of adjuvant chemotherapy with uracil-tegafur for adenocarcinoma of the lung. N Engl J Med 2004; 350: 1713-1721.

4 Winton $\mathrm{T}$, Livingston $\mathrm{R}$, Johnson $\mathrm{D}$, et al. Vinorelbine plus cisplatin vs. observation in resected non-small-cell lung cancer. $N$ Engl $J$ Med 2005; 352: 2589-2597.

5 Douillard JY, Rosell R, De Lena M, et al. Adjuvant vinorelbine plus cisplatin versus observation in patients with completely resected stage IB-IIIA non-small-cell lung cancer (Adjuvant Navelbine International Trialist Association [ANITA]): a randomised controlled trial. Lancet Oncol 2006; 7: 719-727.

6 Strauss GM, Herndon JE, Maddaus MA, et al. Adjuvant paclitaxel plus carboplatin compared with observation in stage IB non-smallcell lung cancer: CALGB 9633 with the Cancer and Leukemia Group B, Radiation Therapy Oncology Group, and North Central Cancer Treatment Group Study Groups. J Clin Oncol 2008; 26: 5043-5051.

7 Ellis P, Fagan BM, Magness ST, et al. SOX2, a persistent marker for multipotential neural stem cells derived from embryonic stem cells, the embryo or the adult. Dev Neurosci 2004; 26: 148-165.

8 Takahashi K, Yamanaka S. Induction of pluripotent stem cells from mouse embryonic and adult fibroblast cultures by defined factors. Cell 2006; 126: 663-676.

9 Karoubi G, Cortes-Dericks L, Gugger M, et al. Atypical expression and distribution of embryonic stem cell marker, OCT4, in human lung adenocarcinoma. J Surg Oncol 2010; 102: 689-698.

10 Meng HM, Zheng $\mathrm{P}$, Wang $X Y$, et al. Overexpression of nanog predicts tumour progression and poor prognosis in colorectal cancer. Cancer Biol Ther 2010; 9: 295-302.

11 Sholl LM, Long KB, Hornick JL. Sox2 expression in pulmonary non-small cell and neuroendocrine carcinomas. Appl Immunohistochem Mol Morphol 2010; 18: 55-61.

12 Bass AJ, Watanabe $\mathrm{H}$, Mermel $\mathrm{CH}$, et al. SOX2 is an amplified lineage-survival oncogene in lung and esophageal squamous cell carcinomas. Nat Genet 2009; 41: 1238-1242.

13 McCaughan F, Pole JC, Bankier AT, et al. Progressive 3q amplification consistently targets SOX2 in preinvasive squamous lung cancer. Am J Respir Crit Care Med 2010; 182: 83-91.

14 Ben-Porath I, Thomson MW, Carey VJ, et al. An embryonic stem cell-like gene expression signature in poorly differentiated aggressive human tumours. Nat Genet 2008; 40: 499-507.

15 Hussenet T, Dali S, Exinger J, et al. SOX2 is an oncogene activated by recurrent $3 q 26.3$ amplifications in human lung squamous cell carcinomas. PLoS One 2010; 5: e8960.

$16 \mathrm{Lu} \mathrm{Y,} \mathrm{Futtner} \mathrm{C,} \mathrm{Rock} \mathrm{JR,} \mathrm{et} \mathrm{al.} \mathrm{Evidence} \mathrm{that} \mathrm{SOX2} \mathrm{overexpression}$ is oncogenic in the lung. PLoS One 2010; 5: e11022.

17 Sholl LM, Barletta JA, Yeap BY, et al. Sox2 protein expression is an independent poor prognostic indicator in stage I lung adenocarcinoma. Am J Surg Pathol 2010; 34: 1193-1198.

18 Barroso-delJesus A, Romero-Lopez C, Lucena-Aguilar G, et al. Embryonic stem cell-specific miR302-367 cluster: human gene structure and functional characterization of its core promoter. Mol Cell Biol 2008; 28: 6609-6619.

19 Card DA, Hebbar PB, Li L, et al. Oct4/Sox2-regulated miR-302 targets cyclin D1 in human embryonic stem cells. Mol Cell Biol 2008; 28: 6426-6438.

$20 \mathrm{Xu} \mathrm{N}$, Papagiannakopoulos T, Pan G, et al. MicroRNA-145 regulates OCT4, SOX2, and KLF4 and represses pluripotency in human embryonic stem cells. Cell 2009; 137: 647-658.

21 Sachdeva M, Zhu S, Wu F, et al. p53 represses c-Myc through induction of the tumour suppressor miR-145. Proc Natl Acad Sci USA 2009; 106: 3207-3212.

22 Navarro A, Marrades RM, Vinolas N, et al. MicroRNAs expressed during lung cancer development are expressed in human pseudoglandular lung embryogenesis. Oncology 2009; 76: 162-169.

23 Peltier HJ, Latham GJ. Normalization of microRNA expression levels in quantitative RT-PCR assays: identification of suitable 
reference RNA targets in normal and cancerous human solid tissues. RNA 2008; 14: 844-852.

24 Hothorn T, Lausen B. On the exact distribution of maximally selected rank statistics. Comput Stat Data Anal 2003; 43: 121-137.

25 Suzuki HI, Yamagata K, Sugimoto K, et al. Modulation of microRNA processing by p53. Nature 2009; 460: 529-533.

26 Nichols J, Zevnik B, Anastassiadis K, et al. Formation of pluripotent stem cells in the mammalian embryo depends on the POU transcription factor Oct4. Cell 1998; 95: 379-391.

27 Kellner S, Kikyo N. Transcriptional regulation of the Oct4 gene, a master gene for pluripotency. Histol Histopathol 2010; 25: 405-412.

28 Lin SL, Chang DC, Chang-Lin S, et al. Mir-302 reprograms human skin cancer cells into a pluripotent ES-cell-like state. RNA 2008; 14: 2115-2124.
29 Yin R, Zhang S, Wu Y, et al. microRNA-145 suppresses lung adenocarcinoma-initiating cell proliferation by targeting OCT4. Oncol Rep 2011; 25: 1747-1754.

30 Barroso-del Jesus A, Lucena-Aguilar G, Menendez P. The miR302-367 cluster as a potential stemness regulator in ESCs. Cell Cycle 2009; 8: 394-398.

31 Xiang R, Liao D, Cheng T, et al. Downregulation of transcription factor SOX2 in cancer stem cells suppresses growth and metastasis of lung cancer. Br J Cancer 2011; 104: 1410-1417.

32 Suh SO, Chen Y, Zaman MS, et al. MicroRNA-145 is regulated by DNA methylation and p53 gene mutation in prostate cancer. Carcinogenesis 2011; 32: 772-778.

33 Kajstura J, Rota M, Hall SR, et al. Evidence for human lung stem cells. N Engl J Med 2011; 364: 1795-1806. 